\title{
PATHOLOGICAL VARIATIONS IN BLOOD AND SPINAL FLUID PYRUVIC ACID ${ }^{1}$
}

\author{
BY ERNEST BUEDING, HERMAN WORTIS, AND MARVIN STERN \\ WITH THE TECHNICAL ASSISTANCE OF DOROTHY ESTURONNE \\ (From the Medical Service of the Psychiatric Division, Bellevue Hospital, New York City, and \\ the Departments of Psychiatry and Medicine, New York University College of \\ Medicine, New York City)
}

(Received for publication September 11, 1941)

Pyruvic acid is a normal intermediary of carbohydrate metabolism $(1,2)$. It has been previously demonstrated that thiamin, or more particularly thiamin pyrophosphate (cocarboxylase), is concerned in the normal catabolism of pyruvic acid (1). In Oriental beri-beri (3) and peripheral neuropathy in the alcohol addict (4)-both diseases associated with a deficiency of thiaminhyperpyruvemia does occur.

Pyruvic acid is a keto acid and therefore a bisulfite binding substance. Previous investigators (5, $6,7)$ have frequently used the measurement of the total bisulfite binding substances (B.B.S.) as an indication of the pyruvic acid level of the blood. More recent work $(8,9,10,11)$ indicates that this is not justified and that a more specific method for pyruvic acid must be used.

Utilizing such a method, we have determined the concentration of pyruvic acid in 60 normal subjects (12). The figures varied from 0.77 to $1.16 \mathrm{mgm}$. per cent, the average being $0.98 \mathrm{mgm}$. per cent. We have considered as abnormally high cases with blood pyruvic acid levels above 1.30 mgm. per cent. The spinal fluid pyruvate is 70 to 120 per cent of a corresponding blood sample (average 82 per cent) (13).

The present study was undertaken in order to determine the clinical significance of the pyruvic acid levels in blood and cerebrospinal fluid.

\section{MATERIALS AND METHODS}

Pyruvic acid was determined in the blood by a method previously described $(12,14)$. Spinal fluid pyruvate was determined similarly, except that it was found that the stabilizing medium (monoiodoacetate) was unnecessary. All samples

1 Aided by grants from the John and Mary R. Markle Foundation, the Williams-Waterman Fund of the Research Corporation, and an Anonymous Donor for Research in Psychosomatic Medicine. were obtained in fasting subjects at complete bed rest.

\section{RESULTS}

\section{(A) Normal individuals}

Blood pyruvic acid was determined in 41 normal individuals (internes, laboratory workers, attending physicians). The figures varied from 0.77 to $1.23 \mathrm{mgm}$. per cent (average 1.02).

\section{(B) "Acute" peripheral neuropathy}

Blood determinations were done on 48 individuals. The figures ranged from 1.00 to 3.63 mgm. per cent (average 1.88). Three had figures below $1.30 \mathrm{mgm}$. per cent, the accepted normal. In 23 of these individuals, spinal fluid pyruvic acid determinations were done. The figures ranged from 1.00 to $2.37 \mathrm{mgm}$. per cent (average 1.64). We (15) have previously indicated that all these cases of "acute" peripheral neuropathy were associated with some type of cortical dysfunction. This group included 11 cases of Wernicke's syndrome, a disease known to be associated with a deficiency of thiamin $(16,17)$, and the others showed various types of encephalopathy, including Korsakoff syndrome, delirium tremens, nicotinic acid deficiency and other less serious types of cortical dysfunction. In 3 individuals, the "acute" peripheral neuropathy was associated with beriberi heart disease.

\section{(C) Chronic peripheral neuropathy}

These cases include (a) those who had received adequate vitamin therapy without a complete return to normal functioning of the peripheral nerves, or $(b)$ individuals who had been on hospitals diets for some time.

Blood determinations were done on 25 such cases with figures ranging from 0.85 to $1.31 \mathrm{mgm}$. 


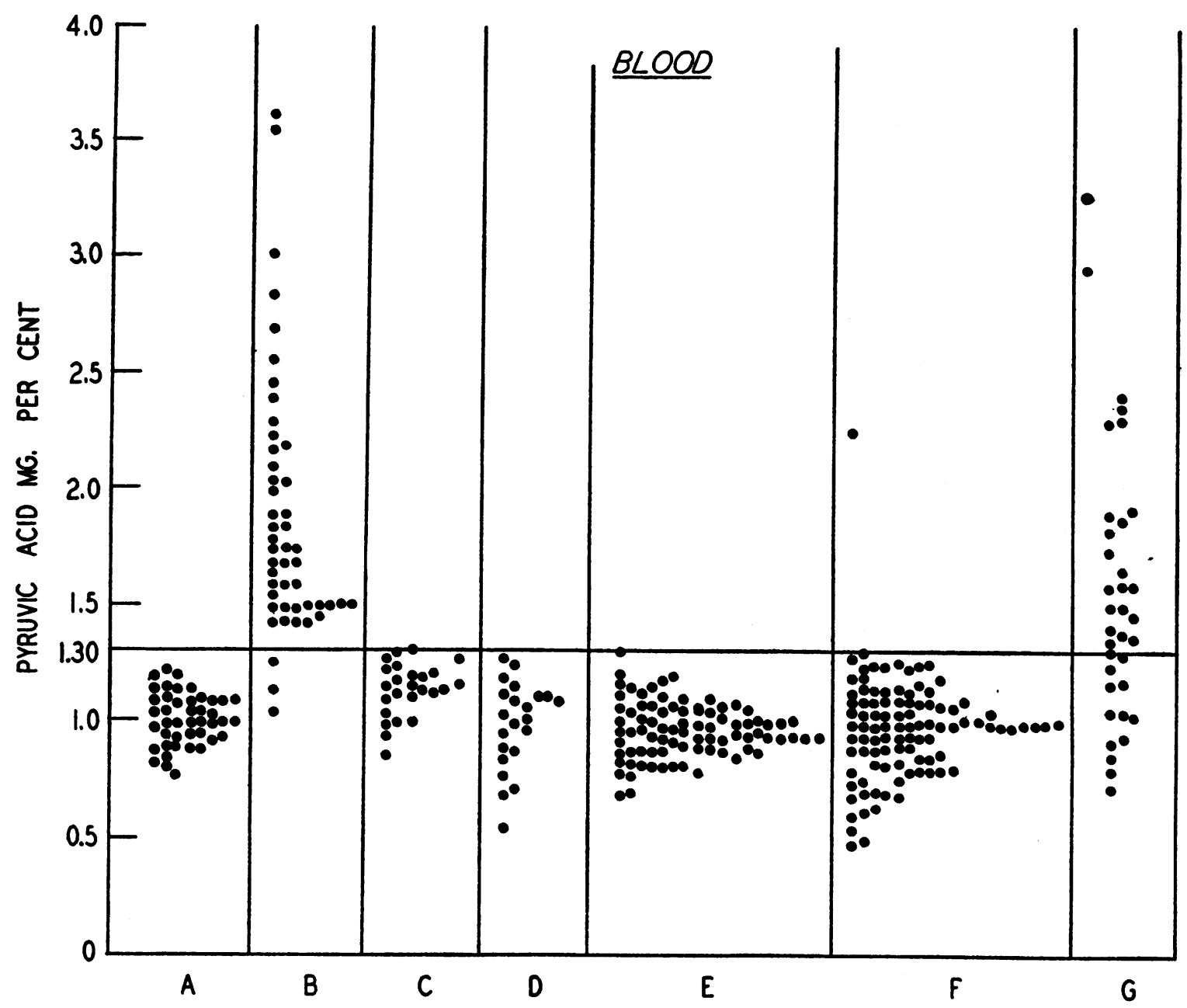

Fig. 1. Blood Pyruvic Acid
A. Normal individuals
B. "Acute" peripheral neuropathy
C. Chronic peripheral neuropathy
D. Chronic alcoholics with no objective evidence of nutritional deficiency
E. Psychiatric disorders
F. Medical disorders (no febrile reaction)
G. Fever

per cent (average 1.12). In 10 of these cases, pyruvic acid was determined in the spinal fluid. The figures ranged from 0.83 to $1.31 \mathrm{mgm}$. per cent (average 1.07).

(D) Chronic alcoholics with no objective evidence of nutritional deficiency

Blood pyruvic acid was determined on 22 such individuals. The figures ranged from 0.54 to $1.27 \mathrm{mgm}$. per cent (average 0.99). In 13 of these individuals, the spinal fluid pyruvate ranged from 0.60 to $1.26 \mathrm{mgm}$. per cent (average 0.96 ).
(E) Psychiatric disorders with no objective evidence of nutritional deficiency

Determinations were done on the following:

\begin{tabular}{lrc}
\hline \multicolumn{1}{c}{ Diagnostic grouping } & $\begin{array}{c}\text { Blood } \\
\text { Number } \\
\text { of cases }\end{array}$ & $\begin{array}{c}\text { Spinal fluid } \\
\text { Number } \\
\text { of cases }\end{array}$ \\
\hline Schizophrenia & 22 & 24 \\
Manic-depressive (depressed) & 2 & 4 \\
Involutional melancholia & 6 & 1 \\
Reactive depression & 7 & 1 \\
Behavior disorders in children & 27 & 13 \\
Behavior disorders associated with mental & 5 & 8 \\
deficiency & 8 & 2 \\
Psychopathic personality & 8 & 0 \\
Psychoneurosis & 5 & \\
\hline
\end{tabular}


All figures in these groups fell within the normal range. The blood figures varied from 0.70 to $1.29 \mathrm{mgm}$. per cent; the spinal fluid from 0.42 to 1.22 mgm. per cent.

\section{(F) Medical disorders (no febrile reaction)}

Determinations were done on the following:

\begin{tabular}{lcc}
\hline \hline \multicolumn{1}{c}{ Diagnosis } & $\begin{array}{c}\text { Blood } \\
\text { Number } \\
\text { of cases }\end{array}$ & $\begin{array}{c}\text { Spinal fluid } \\
\text { Number } \\
\text { of cases }\end{array}$ \\
\hline Generalized arteriosclerosis & 16 & 4 \\
Hypertensive vascular disease & 14 & 0 \\
Diabetes mellitus & 11 & 0 \\
Central nervous system syphilis & 10 & 5 \\
Mild cardiac failure (not agitated or & 10 & 0 \\
dyspneic) & 4 & 0 \\
Chronic diffuse glomerulonephritis & 3 & 3 \\
Paroxysmal convulsive disorder & 2 & 0 \\
Pellagrous stomatitis (non-alcoholic) & 2 & 0 \\
Cirrhosis of liver & 2 & 0 \\
Pernicious anemia & 2 & 0 \\
Bronchial asthma & 2 & 0 \\
Submersion (aspiration pneumonia) & 0 & 2 \\
Primary brain tumor & & \\
\hline
\end{tabular}

In addition, we studied the blood pyruvic acid in one case each of congenital cerebral aneurysm, generalized syphilis, hyperthyroidism, birth injury, arthritis, cor pulmonale, drug addiction, insulin coma, lysol poisoning, arsenical poisoning, bromide poisoning, barbiturate poisoning, carcinoma of the prostate, bronchopneumonia, lead neuropathy, Little's disease, congenital aphasia, multiple sclerosis, spinal cord tumor, cortical atrophy, meningo-encephalitis of undetermined etiology. Spinal fluid pyruvate was determined in one case each of hyperthyroidism, Little's disease, and arsenical poisoning. The figures in the blood and cerebrospinal fluid were normal in every instance but one. This was a case of lymphoepithelioma of the pharynx with associated cachexia. Blood pyruvic acid in this case was $2.32 \mathrm{mgm}$. per cent. Determination of vitamin $B_{1}$ in the blood yielded an abnormally low figure (1.82 gamma).

Mention must also be made of a paper by Yanof (18) who reports blood pyruvate levels of $3 \mathrm{mgm}$.

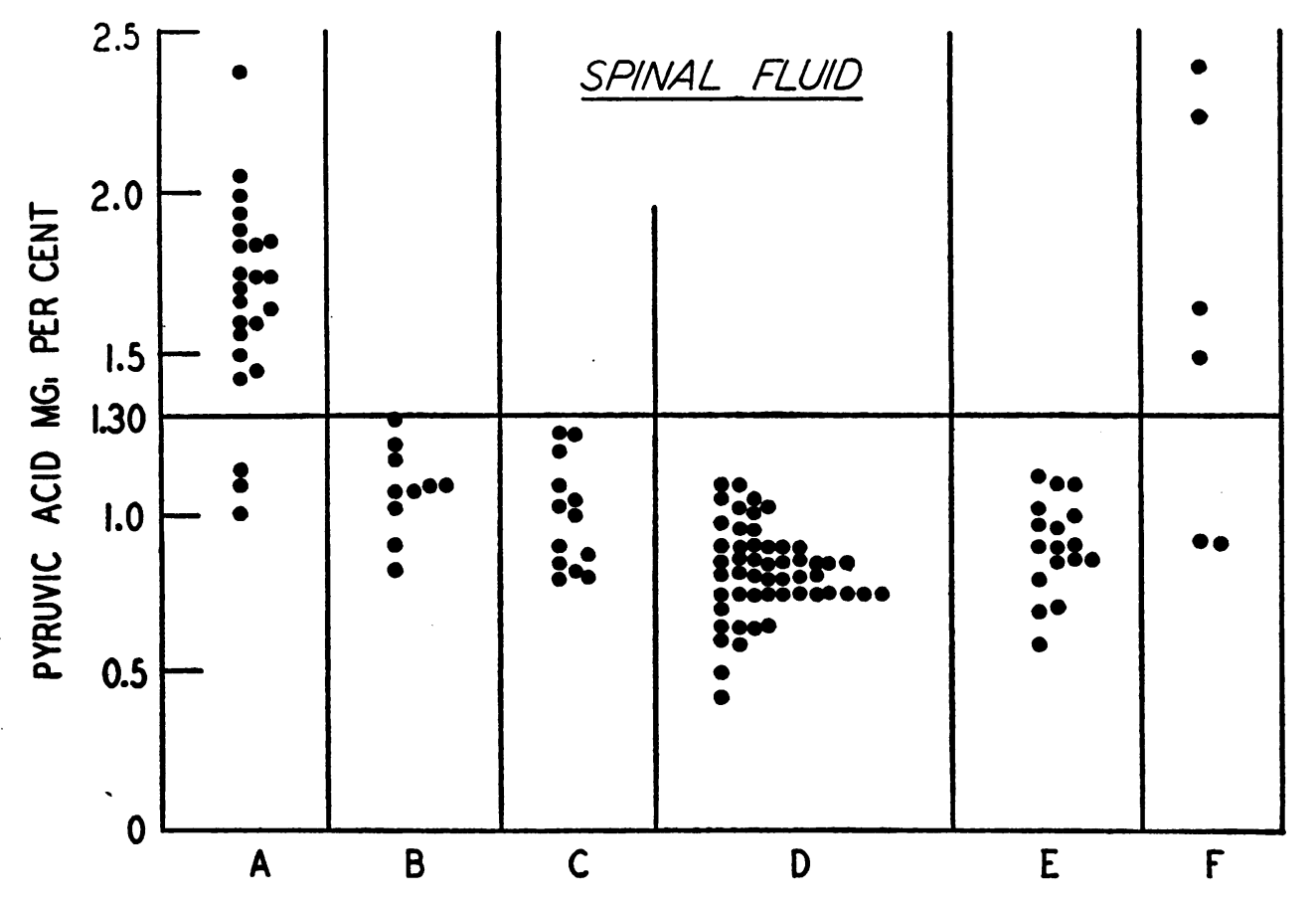

Fig. 2. Spinal Fluid Pyruvic Acid
A. "Acute" peripheral neuropathy
B. Chronic peripheral neuropathy
C. Chronic alcoholics with no objective evidence of nutritional deficiency
D. Psychiatric disorders
E. Medical disorders (no febrile reaction)
F. Fever 
per cent in cases of decompensated heart disease. These figures may be the result of (1) agitation and increased muscular activity and (2) glycolysis following hypoxemia. That the elevated figures obtained by the author are not invariably associated with cardiac decompensation as such is evidenced by our findings in 10 non-agitated cases of mild cardiac failure.

\section{(G) Fever}

These cases represent a very heterogeneous grouping, the common factor being an elevation of temperature of varying degree and duration. They include cases of meningitis, pneumonia, carbon-monoxide poisoning, cerebral accidents, therapeutic malaria, erysipelas, etc. Thirty-five blood determinations were done, of which 22 were above the accepted normal (1.30 mgm. per cent). In 6 instances, spinal fluid pyruvate determinations were done, and in 4 of these the figures were definitely elevated.

\section{DISCUSSION}

It will be noted that two groups of cases showed an abnormal elevation of blood and spinal fluid pyruvates: (a) those associated with nutritional deficiency (45 cases of "acute" peripheral neuropathy and 1 case of lymphoepithelioma with associated cachexia), and (b) 22 cases associated with an elevation in temperature. The first group is readily explained by the fact that thiamin, or more particularly thiamin pyrophosphate, is necessary for the normal catabolism of pyruvic acid. Since it is now generally accepted that the "acute" peripheral neuropathy of alcohol addicts is associated with a deficiency of thiamin, this defect in pyruvic acid metabolism becomes readily understandable (4). In addition, we have presented evidence suggesting that pyruvic acid is a normal intermediary of carbohydrate catabolism in man $(2,14)$. In normal individuals, there is a significant rise of pyruvic acid after the ingestion of glucose, reaching a maximum at the end of the first hour and returning to normal within three hours (19). In 14 cases of "acute" peripheral neuropathy, the pyruvic acid curve following glucose ingestion was abnormally elevated and prolonged (14). The maximum rise in blood pyruvate was not only greater than that seen in normal indi- viduals, but the elevation above the fasting level was maintained for a period of at least four hours. Furthermore, the maximum rise did not occur at the end of the first hour, as seen in normals, but the pyruvate continued to rise in every instance, and maximal figures were obtained at the end of the second, third or fourth hours. In addition, we have observed that thiamin therapy, alone or in conjunction with other members of the vitamin B complex, corrects this defect in pyruvic acid metabolism (20).

On the other hand, we have noted hyperpyruvemia in 22 cases of hyperpyrexia unassociated with any clinical evidence of vitamin deficiency. In these cases it may be that the elevation in total metabolism so increases the thiamin requirements that a deficiency occurs with resultant hyperpyruvemia. On the other hand, it should be noted that none of these cases had peripheral neuropathy. This suggests that either the metabolic disturbance must exist for some time before peripheral neuropathy occurs or that hyperpyruvemia may be related to metabolic disturbances other than thiamin deficiency (21). This subject is now under investigation.

We also wish to emphasize that a normal fasting pyruvic acid may not be an invariable evidence of thiamin adequacy. In 1 case of "acute" peripheral neuropathy and 2 cases of "chronic" peripheral neuropathy with normal fasting blood pyruvate, we have observed an abnormal pyruvate curve following glucose ingestion. This suggests that the pyruvic acid curve following glucose ingestion may prove to be a more sensitive index of thiamin adequacy than the fasting blood pyruvic acid level.

\section{SUMMARY AND CONCLUSIONS}

1. Normal fasting pyruvic acid levels are reported in the blood and spinal fluid in cases of "chronic" peripheral neuropathy, chronic alcoholism without objective evidence of nutritional deficiency, various psychiatric and medical disorders and certain cases of hyperpyrexia.

2. Hyperpyruvemia has been noted in cases of "acute" peripheral neuropathy, and in about twothirds of the cases associated with hyperpyrexia.

3. The possible clinical significance of pyruvic acid determinations in the blood and spinal fluid is discussed. 


\section{BIBLIOGRAPHY}

1. Banga, I., Ochoa, S., and Peters, R. A., Pyruvate oxidation in brain; some dialyzable components of the pyruvate oxidation system. Biochem. J., 1939, 33, 1980.

2. Bueding, E., Stein, M. H., and Wortis, H., The formation of pyruvic acid following glucose ingestion in man. J. Biol. Chem., 1941, 139, 793.

3. Lu, G. D., Studies on metabolism of pyruvic acid in normal and vitamin $B_{1}$ deficient states. Biochem. J., 1939, 33, 249.

4. Wortis, H., Bueding, E., and Jolliffe, N., Pyruvic acid studies in the peripheral neuropathy of the alcohol addict. New England J. Med. (In press.)

5. Banerji, G. G., and Harris, L. J., Methods for assessing the level of nutrition; a carbohydrate tolerance test for vitamin $B_{1}$. Part I, Experiments with rats. Biochem. J., 1939, 33, 1346.

6. Platt, B. S., and Lu, G. D., Chemical and clinical findings in beriberi with specific reference to vitamin $B_{1}$ deficiency. Quart. J. Med., 1936, 5, 355.

7. Thompson, R. H. S., and Johnson, R. E., Blood pyruvate in vitamin $B_{1}$ deficiency. Biochem. J., 1935, 29, 694.

8. Robinson, W. D., Melnick, D., and Field, H., Jr., Correlation between the concentration of bisulphite binding substances in the blood and urinary thiamin excretion. J. Clin. Invest., 1940, 19, 483.

9. Wilkins, R. W., Weiss, S., and Taylor, F. H. L., Effect and rate of removal of pyruvic acid administered to normal persons and to patients with and without "vitamin B deficiency." Ann. Int. Med., 1939, 12, 938.

10. Wortis, H., Bueding, E., and Wilson, W. E., Bisulfite binding substances (B.B.S.) in the blood and cerebrospinal fluid. Proc. Soc. Exper. Biol. and Med., 1940, 43, 279.

11. Wortis, H., Bueding, E., and Wilson, W. E., The clinical significance of bisulfite binding substances (B.B.S.) in the blood and cerebrospinal fluid. Am. J. Psychiat., 1940, 97, 573.

12. Bueding, E., and Wortis, H., The stabilization and determination of pyruvic acid in the blood. J. Biol. Chem., 1940, 133, 585.

13. Bueding, E., and Wortis, H., Pyruvic acid in the blood and cerebrospinal fluid. Proc. Soc. Exper. Biol. and Med., 1940, 44, 245.

14. Bueding, E., Stein, M. H., and Wortis, H., Pyruvic acid curves following glucose ingestion in normal and thiamin deficient subjects. J. Biol. Chem., 1941, 140, 697.

15. Wortis, H., and Jolliffe, N., The present status of the vitamins in nervous health and disease. New York State J. Med., 1941, 41, 1461.

16. Alexander, L., Wernicke's disease; identity of lesions produced experimentally by $B_{1}$ avitaminosis in pigeons with hemorrhagic polioencephalitis occurring in chronic alcoholism in man. Am. J. Path., 1940, 16, 61.

17. Jolliffe, N., Wortis, H., and Fein, H. D., The Wernicke syndrome. J. Nerv. and Ment. Dis., 1941, 93, 214.

18. Yanof, Z. A., Blood pyruvic acid in heart disease. Proc. Soc. Exper. Biol. and Med., 1941, 47, 516.

19. Bueding, E., Wortis, H., Stein, M. H., and Jolliffe, N., Pathological variations in blood pyruvic acid. J. Clin. Invest., 1941, 20, 441.

20. Wortis, H., Bueding, E., and Stern, M., Unpublished observations.

21. Wortis, H., and Bueding, E., The clinical significance of pyruvic acid content of blood and cerebrospinal fluid. Tr. Am. Neurol. A., 1940, 66, 90. 